\title{
Evaluation of the critical stress of anodized coating-AZ91D substrate using SEM in-situ technology*
}

\author{
Xi-shu $\mathrm{WANG}^{\dagger 1}$, Xing-wu GUO ${ }^{2}$, Yuzo NAKAMURA ${ }^{3}$, Hui-hui YANG ${ }^{1}$, Pan PAN $^{1}$ \\ ('Applied Mechanics Laboratory, Department of Engineering Mechanics, Tsinghua University, Beijing 100084, China) \\ $\left({ }^{2}\right.$ National Engineering Research Center for Light Alloy Net Forming, School of Material Science \& Engineering, \\ Shanghai Jiao Tong University, Shanghai 200030, China) \\ ( ${ }^{3}$ Department of Mechanical Engineering, Kagoshima University, Kagoshima 890-0065, Japan) \\ †E-mail: xshwang@tsinghua.edu.cn \\ Received June 13, 2015; Revision accepted Nov. 9, 2015; Crosschecked Dec. 16, 2015
}

\begin{abstract}
Experimental investigations of the micro cracking behavior of a coating-substrate structure were carried out $i n$-situ with a scanning electron microscope (SEM). An anodized coating layer was deposited on an AZ91D substrate by the galvanize pulse method. Results indicated that the failure mechanism of the coating-substrate structure was due to a mismatch of micro deformation between the coating and substrate. The micro deformations induced by different failure models were cracking, spalling, or delamination. The failure models were validated using theoretical, experimental, and digital image correlation methods. The critical stress of failure can be evaluated by measuring the biaxial stress.
\end{abstract}

Key words: Magnesium alloy, Anodized coating, Material mechanics, Flexural stress, Cracking behavior http://dx.doi.org/10.1631/jzus.A1500178

CLC number: O343.1; O346.1; O348.3

\section{Introduction}

Light metals, such as magnesium and aluminum alloys, are very attractive structural materials for achieving high performance and energy savings in machines and structures. This is because of their advantages, such as a high strength to weight ratio and high specific stiffness (Mordike and Ebert, 2001). Therefore, the use of light metals (especially magnesium alloys) as structural materials has recently been attracting increasing interest in many applications. In particular, some magnesium alloys are considered to be replacing some aluminum alloys in aerospace and

\footnotetext{
* Project supported by the National Natural Science Foundation of China (Nos. 11272173 and 11572170), and the Foundation of Traction Power State Key Laboratory of Southwest Jiaotong University (No. TPL1503), China

(D) ORCID: Xi-shu WANG, http://orcid.org/0000-0001-6870-6411

(C) Zhejiang University and Springer-Verlag Berlin Heidelberg 2016
}

automobile fields with a concomitant saving in weight, and good casting properties in automotive industries (Dahle et al., 2001; Tang et al., 2005; Wang and Fan, 2006). However, the active chemical reactivity and low fatigue strength of magnesium alloys have deterred many potential users from incorporating magnesium into their designs. Recently, anodizing coatings and plasma electrolytic oxidation (PEO) coatings have become effective methods for improving the corrosion resistance of magnesium alloys (Nykyforchyn et al., 1998; Yerokhin et al., 1999; 2004; 2005; Khan et al., 2005; Guo et al., 2007; Rajasekaran et al., 2008). Unfortunately, some results have indicated that anodized or PEO coatingsubstrate structures have reduced fatigue strength or fatigue life compared with uncoated substrates (Eifert et al., 1999; Yerokhin et al., 2004; 2005; Rajasekaran et al., 2008). Wang et al. (2014; 2015) provided a method for improving the fatigue strength of 
coated-substrate of Al 2024-T4 alloy by using PEO with an impregnation epoxy resin sealing pore method. One of reasons for the improvement in fatigue strength was that the PEO coating with impregnation epoxy resin not only "welds" the original thermal cracks, but also fills in the micro pores or meso pits previously formed in the PEO coating process or hard anodized process. This so-called synergistic effect between coating and substrate is able significantly to improve the surface fatigue crack initiation resistance and the fatigue crack propagation resistance. However, it is still unclear how the relations of the interface influence the surface deformation and micro cracking behavior of the coatingsubstrate structure, especially how to evaluate critical stress failure in the coating layer or substrate. For example, little is known about the effect of increasing the coating thickness or adding multiple coating layers, or the effect of the interface on crack initiation and propagation mechanisms in the micro scale. Although Tvergaard $(2001 ; 2004)$ reported interface crack nucleation and growth under mixed mode loading conditions based on special interface elements in theory, relevant experimental results have rarely been reported. In addition, the suitability of elastic mechanics theories and finite element (FE) methods for thin anodized coatings (hard thickness layers) and relatively thick substrates (relatively soft thickness layers) has been debated. This is because the elastic theories used to evaluate the failure stress are based on the plane strain state which assumes that the effect of width of coating layer on the strain or stress can be ignored. On the other hand, there are difficulties in mesh refinement using the FE method (Hutchinson and Suo, 1991; Fawcett, 1998; Yan and White, 1999; Michler and Blank, 2001; Zhao et al., 2002; Schwaiger and Kraft, 2003; Yang et al., 2014; Dean et al., 2015). Therefore, to investigate failure issues of thin coating layers/substrates, experimental study is the best and directly approach (Wang and Xu, 2003; 2004; Wang et al., 2004; 2009; Li et al., 2008a; 2008b; Dean et al., 2015). In addition, it is necessary to estimate the delivery criterion of stress close to the interface of thin anodized coatings and thick substrates using SEM in-situ technology (Wang et al., 2004; Wang and Fan, 2006; Jia et al., 2012; Ren et al., 2013; Ren and Wang, 2014).

\section{Testing sample preparation and method}

All specimens consisted of an anodized $\mathrm{MgO}$ coating and AZ91D substrate with a rectangular cross-section $(30 \mathrm{~mm} \times 5 \mathrm{~mm} \times 2 \mathrm{~mm})$. Experiments were carried out by SEM in-situ observation under a three-point bending loading (Fig. 1a). The sample subjected to the bending loading was inserted into the vacuum chamber of the SEM system (Fig. 1b). Force diagrams of a sample with a two-layerlaminated beam are shown in Figs. 1a and 1c.

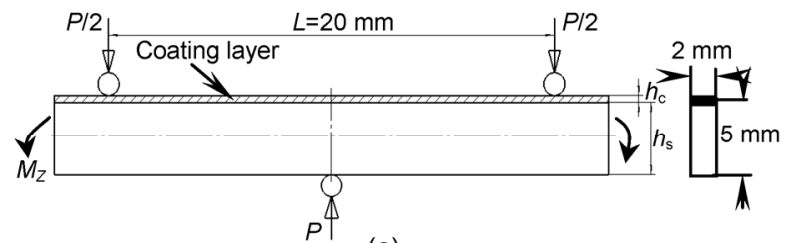

(a)

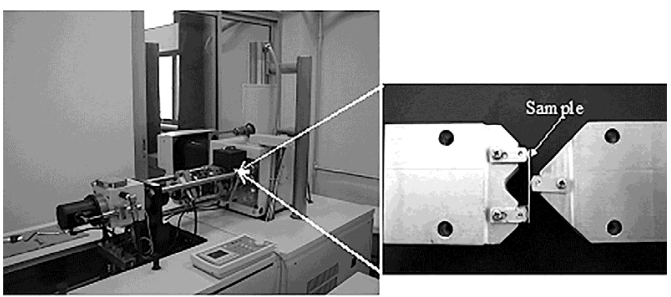

(b)

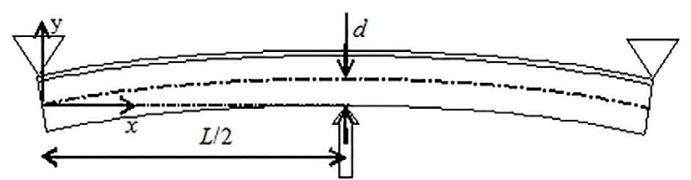

(c)

Fig. 1 A schematic of the coating-substrate structure based on SEM in-situ technology

(a) Shape and size of the sample; (b) Experimental methodology; (c) Mechanics model of a two-layer-laminated beam. $L$ is the span length, $M_{z}$ is the bending moment, $h_{\mathrm{c}}$ and $h_{\mathrm{s}}$ are the thickness of the coating and substrate, respectively, $d$ is the displacement of neutral axis, and $P$ is the applied loading

The chemical composition of the AZ91D substrate was $9.50 \% \mathrm{Al}, 0.90 \% \mathrm{Zn}, 0.17 \% \mathrm{Mn}, 0.05 \%$ $\mathrm{Si}$ in weight, with very low contents of copper, iron, and nickel. The anodized coating on the AZ91D substrate was prepared by a galvanostatic pulse technique in $\mathrm{K}_{2} \mathrm{SiO}_{3}+\mathrm{KOH}+\mathrm{KF}$ solutions with a small quantity of proprietary additives for about $15 \mathrm{~min}$. The square pulse current had an average current density $i_{\mathrm{m}}$ of $0.05-0.1 \mathrm{~A} / \mathrm{cm}^{2}$, the frequency $f$ was $1000 \mathrm{~Hz}$ and the ratio $(\alpha)$ of switch time on $\left(t_{\text {on }}\right)$ to 
switch time off $\left(t_{\text {off }}\right)\left(\alpha=t_{\text {on }}: t_{\text {off }}\right)$ was about $5 \%$. The solution temperature was about $30{ }^{\circ} \mathrm{C}$ and the two end voltages were $330 \mathrm{~V}$ and $350 \mathrm{~V}$, respectively. The thickness of the anodized coating layer measured from the cross-section of the coating-substrate using the SEM was about 30-40 $\mu \mathrm{m}$ (Fig. 2a). Some micro voids of about $1 \mu \mathrm{m}$ in size were present in the cross-section of the coating layer. These micro voids resulted from the release of residual stress during the anodized coating process. Therefore, the residual stress in the anodized coating was ignored. In addition, the interface between the anodized coating and the AZ91D substrate had a better integrality (Fig. 2a), although the interface was not regular, as shown by the arrows in Fig. 2a, where there is neither interface cracking nor debonding in the region of observation. The free surface microstructure of the anodized coating is shown in Fig. 2b. The free surface roughness was estimated to be about $R_{\mathrm{a}}=0.3-0.5 \mu \mathrm{m}$ using an atomic force microscope (AFM) so as not to cause a change in the stress in the coating layer.

(a)

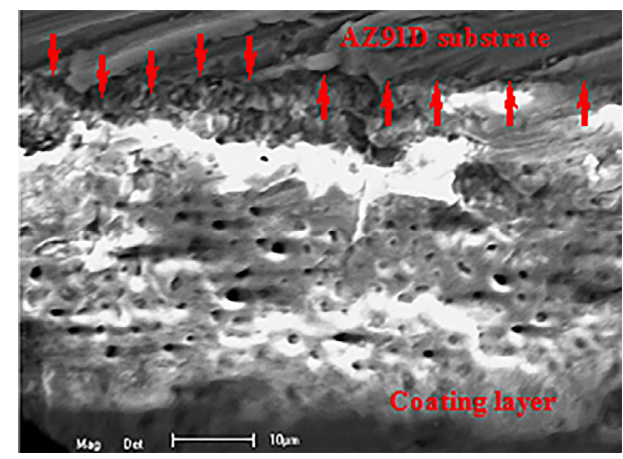

(b)

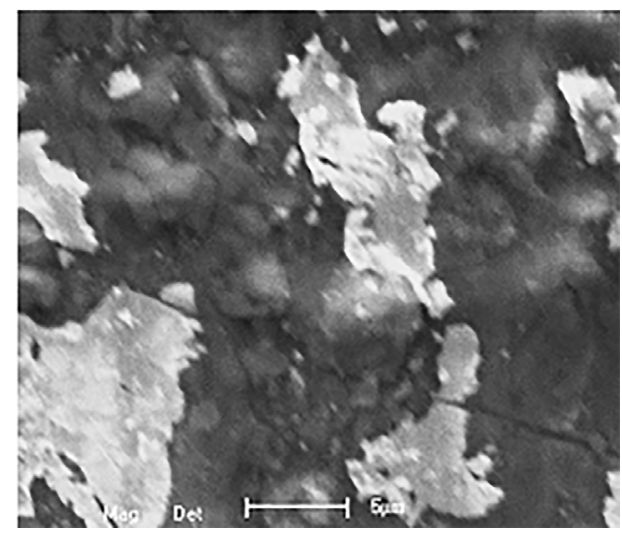

Fig. 2 Microstructures at the interface and surface of the coating-substrate structure

(a) Cross-section image (scale bar $10 \mu \mathrm{m}$ ); (b) Free surface image (scale bar $5 \mu \mathrm{m}$ )
The main mechanical properties of the anodized coating-substrate structure are listed in Table 1. The Young's modulus of the anodized coating-AZ91D substrate and AZ91 alloy are similar (KonstaGdoutos and Gdoutos, 2005). However, the strength and elongation of the anodized coating-AZ91D substrate were lower than those of the AZ91D bulk substrate. One of reasons is that the sample can be defined as composite layers of structural material so that the strength and toughness of the structural material decreases with increasing thickness of the coating (Li et al., 2002).

The micro crack initiation and propagation tests of the anodized coating-AZ91D substrate were carried out using SEM in-situ observation at room temperature in a vacuum chamber $\left(10^{-4} \mathrm{~Pa}\right)$ (Figs. 1b and 1c). To achieve a good roughness $R_{\mathrm{a}}$ of the observation cross-section ( $R_{\mathrm{a}}$ was about $\left.0.8-0.9 \mu \mathrm{m}\right)$, each cross-section was carefully polished with P1000-P2000 (grits page) abrasive papers before the bending tests were carried out (Fig. 2a). A signal from the SEM was directly transferred to a computer via a direct memory access type A/D converter, making it possible to sample $960 \times 1280$ frames of SEM images successively in in-situ observation during the bending test. All bending tests were controlled by a stroke ratio of $10^{-4} \mathrm{~mm} / \mathrm{min}$ (Wang et al., 2004; Wang and Fan, 2006; Huang et al., 2007; Jia et al., 2012; Ren et al., 2013; Ren and Wang, 2014).

\section{Theoretical background}

This method is based on the neutral axis maintaining its original position achieved through a side anodized specimen (Fig. 1c). The two-layerlaminated beam was subjected to a bending moment $M$ and shear force $S$. The coating layer and AZ91D substrate were assumed to display elastic-plastic behavior (Stoney, 1909; Ren et al., 2013; Dean et al., 2015). For a relatively thin coating and relatively low substrate stiffness, the inside stress gradient can be ignored. The shear force $S$ and bending moment $M$, at a distance of $x$ from the edge in a three-point bending test (Fig. 1c), are given by

$$
\begin{aligned}
& S_{x}=P / 2, M_{x}=P x / 2, \quad 0<x<L / 2, \\
& S_{x}=-P / 2, M_{x}=P L / 2-P x / 2, \quad L / 2<x<L .
\end{aligned}
$$


Table 1 Mechanical properties of the anodized coating-substrate structure

\begin{tabular}{cccccr}
\hline Coating-substrate system & $E(\mathrm{GPa})$ & Poisson's ratio & $\sigma_{0.2}(\mathrm{MPa})$ & $\sigma_{\mathrm{b}}(\mathrm{MPa})$ & $\delta(\%)$ \\
\hline Coating-substrate in 330 V & 42 & 0.385 & 100 & 169 & 5.7 \\
Coating-substrate in 350 V & 42 & 0.385 & 96 & 164 & 5.1 \\
AZ91D bulk substrate & 42 & 0.390 & 170 & 203 & 10.2 \\
Coating layer & 37 & 0.350 & & &
\end{tabular}

$\sigma_{\mathrm{b}}$ is the uniaxial tensile strength, $\sigma_{0.2}$ is the yield strength, $\delta$ is the percentage elongation, and $E$ is Young's modulus of the anodized coating-substrate structure

The shear stress $\tau_{\mathrm{s}}$ is taken up mainly by the interface of the substrate (Fig. 1c). The tensile stress $\sigma_{\mathrm{c}}$ is able to be estimated roughly using the so-called Stoney equation (Stoney, 1909) as follows:

$$
\sigma_{\mathrm{c}} \cong \frac{E_{\mathrm{s}} h_{\mathrm{s}}^{2}}{6 R h_{\mathrm{c}}}
$$

where the subscripts $\mathrm{s}$ and $\mathrm{c}$ denote the substrate and coating element, respectively, and $E_{\mathrm{s}}$ is Young's modulus of the AZ91D alloy. Therefore, the bended curvature radius $R$ can be determined based on the known span $L, h\left(h=h_{\mathrm{c}}+h_{\mathrm{s}}\right)$, and the measurable parameter $d$ in the SEM in-situ testing process can be approximately expressed by

$$
\begin{aligned}
R^{2} & =\left(\frac{L}{2}\right)^{2}+(R-d)^{2}, \\
R & =\frac{1}{8 h}\left(L^{2}+4 d^{2}\right),
\end{aligned}
$$

where the displacement $d$, as shown in Fig. 1c, can be indirectly and accurately measured by the SEM in-situ bending process.

Due to strain compatibility at the interface of the coating-substrate, the maximum tensile stress in the substrate $\sigma_{\mathrm{s}}$ (Fig. 1) occurs at the interface of the coating-substrate and is given as follows (Fawcett, 1998; Konsta-Gdoutos and Gdoutos, 2005):

$$
\sigma_{\mathrm{s}} \cong \frac{M_{x}}{b h_{\mathrm{c}} h_{\mathrm{s}}} \frac{E_{\mathrm{s}}}{E_{\mathrm{c}}},
$$

where $E_{\mathrm{c}}$ is Young's modulus of the coating material, and $b(2 \mathrm{~mm})$ is the width of the beam. Li et al. (2002) proposed the formula shown in Eq. (3) for estimating Young's modulus. The benefit of this method is that the $E$ value obtained represents the overall property of the bulk coating. Therefore, Young's modulus of the anodized coating layer was also calculated as follows, according to $E_{\mathrm{s}}$ :

$$
\begin{aligned}
& 2 I_{\mathrm{c}} E_{\mathrm{c}}+I_{\mathrm{s}} E_{\mathrm{s}}=\frac{P L^{3}}{48 d}, \\
& I_{\mathrm{c}}=\int_{h_{\mathrm{s}} / 2}^{h_{\mathrm{c}}+h_{\mathrm{s}} / 2} y^{2} b \mathrm{~d} y, I_{\mathrm{s}}=\int_{-h_{\mathrm{s}} / 2}^{h_{\mathrm{s}} / 2} y^{2} b \mathrm{~d} y,
\end{aligned}
$$

where $I_{\mathrm{c}}$ and $I_{\mathrm{s}}$ are the moments of inertia coating and substrate, respectively.

The shear stress $\tau_{\mathrm{s}}$ in the substrate is given by

$$
\tau_{\mathrm{s}}=\frac{S_{x}}{b h_{\mathrm{s}}}
$$

When the normal stress in the substrate is small relative to the shear stress, it can be assumed that substrate failure occurs when the shear stress reaches the critical value of interface bonding strength. Therefore, the critical failure stress either in the coating layer or at the surface of the substrate occurs when the distance $x$ is $L / 2$.

The presence of a stress or deformation gradient on the coating-substrate structure under the bending test is important in the evaluation of the mechanical behavior of the anodized coating-substrate. The stress distribution in the close vicinity of the coating layer needs to be effectively determined, although the stress gradient in the coating layer can be ignored. Hutchinson and Suo (1991) investigated mixed mode cracking in an interface with different materials from essential mechanics analysis, but the inside stress or strain at the coating layer was not determined, and in particular, there were no experimental data related to the thin coating-film-substrate structure. Yan and White (1999) showed how to estimate the residual stress in the coating layer using an experimental method based on the thickness of both the coating and substrate. 
In this study, the flexural stress was estimated using Eq. (7) from Wang et al. (2009) and Eq. (8) from Yan and White (1999). These equations adequately consider the effect of transversal strain on the longitudinal stress. Biaxial stress is different from the Stoney equation (axial stress) in that the flexural stress involves the indirectly measurable parameters of the biaxial elastic modulus and radius of flexion for a two-layer beam.

$$
\sigma_{\mathrm{c}}=E_{\text {equ. }} \frac{h_{\mathrm{s}}^{2}}{6 h_{\mathrm{c}} R}
$$

where $E_{\text {equ. }}=\left[E_{\mathrm{s}} /\left(1-v_{\mathrm{s}}\right)\right]$ is the biaxial elastic modulus of the coating-substrate, $v_{\mathrm{s}}$ is the Poisson's ratio of the AZ91D substrate (Table 1 ), and $\sigma_{\mathrm{c}}$ is the biaxial stress in the coating, which is defined as the restrained stress. A measurement of the flexural stress can be estimated based on the thickness of the coating, Young's modulus, and Poisson's ratio as follows (Yan and White, 1999):

$$
\begin{aligned}
\sigma_{\mathrm{c}}= & \frac{h_{\mathrm{c}} E_{\mathrm{c}}}{6 R\left(1-v_{\mathrm{c}}\right)} \\
& \times \frac{\left(1+4 \alpha \beta+6 \alpha^{2} \beta+4 \alpha^{3} \beta+\alpha^{4} \beta^{2}\right)}{(1+\alpha)(1+\alpha \beta)},
\end{aligned}
$$

where $\alpha=\frac{h_{\mathrm{s}}}{h_{\mathrm{c}}}, \beta=\frac{E_{\mathrm{s}}\left(1-v_{\mathrm{c}}\right)}{E_{\mathrm{c}}\left(1-v_{\mathrm{s}}\right)}$, and $v_{\mathrm{c}}$ is Poisson's ratio of the coating layer. The thinner the coating layer, the more difficult it is to measure Poisson's ratio. In addition, as $h_{\mathrm{c}} \ll h_{\mathrm{s}}, p \approx h_{\mathrm{s}} / 2$ ( $p$ is the distance of the neutral axial from the coating-substrate interface). $z$ is the size of the interface layer between the coating layer and the substrate thickness, so $z$ is defined as 0 in the anodized coating-substrate because the interface layer was enough small (about 1-5 $\mu \mathrm{m}$ ) (Fig. 2a) to be ignored.

According to the parameters in Table 1 and methods for estimating biaxial stress from Eqs. (7) and (8), which differ mainly in their simplicity and convenience, the surface flexural stresses were considered the obvious effects of the thin coating and mechanical properties. Note that the flexural stress in Eq. (7) depends mainly on the elastic properties of the substrate and the geometric relations of the coating-substrate structure. Typically, the thickness of the anodized coating layer is about $30-40 \mu \mathrm{m}$, and the ratio of the thickness is about 100 . In such cases, the equivalent Young's modulus is completely dominated by the properties $\left(E_{\mathrm{s}}\right.$ and $\left.v_{\mathrm{s}}\right)$ of the substrate.

\section{Results and discussion}

\subsection{Quantitative analysis of flexural stress based on SEM in-situ observation}

Fig. 3 shows the relationship between the flexural stress and the stroke displacement $(d)$, which is defined as the displacement of the indenter, calculated using three different methods based on Eq. (7), Eq. (8) (Yan and White, 1999), and the flexural stress equation for a traditional beam, as follows:

$$
\sigma=\frac{M_{x}(h) y}{I_{z}}
$$

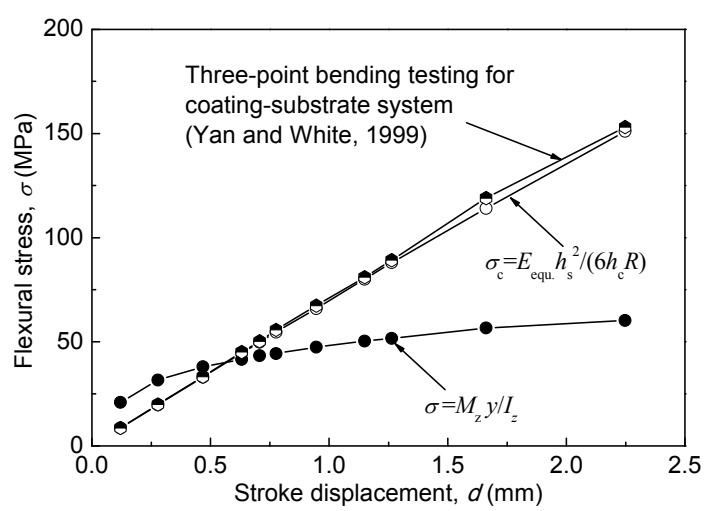

Fig. 3 Relationship between flexural stress and stroke displacement

The moment $M_{x=\text { const. }}$ is a function of the stroke displacement or the flexural radius of the two-layer beam. The flexural stresses measured using the three methods are plotted in Fig. 3. These results indicate that the stresses determined by Eq. (7) and the previous method (Yan and White, 1999) were similar, but the results from using the traditional method based on Eq. (9) differed somewhat from those obtained using Eqs. (7) and (8). One of the reasons is that the effect of the coating layer on the estimated stress in elastic-plastic scope is ignored and the method based on Eq. (9) does not satisfy the requirement of plane strain assumed theory. 
To explain clearly how the flexural stress varied with the deformation of the beam, the curves of flexural stress based on the different methods are given in Fig. 4. As the flexural radius changed from 0 to $100 \mathrm{~mm}$ and the displacement $d$ changed from 0 to $1.8 \mathrm{~mm}$, the flexural stresses decreased more rapidly based on Eqs. (7) and (8) than it did using the traditional method. Thus, with slight variation in the flexural radius, the flexural stress at the coating layer showed observable variation. The inflexions of curves based on the results from Eqs. (7) and (8) suggest that failure occurs easily during the inflexion process, because the coating layer of the beam might be subjected to plastic deformation. That is, when the flexural radius of the beam varied from $79 \mathrm{~mm}$ to $50 \mathrm{~mm}$, the flexural stress at the free surface of the coating layer increased from $45 \mathrm{MPa}$ to $80 \mathrm{MPa}$. This can be approximately transformed $(\varepsilon=\sigma / E)$ in the elastic-plastic region with the corresponding strain values of $122 \mu \varepsilon(45 \mathrm{MPa})$ and $2160 \mu \varepsilon$ $(80 \mathrm{MPa})$ at the coating surface. As a general materials mechanics concept, when the engineering strain is equal to $2000 \mu \varepsilon$, the strength of the material is able to define the offset yield strength. Therefore, plastic deformation may have occurred at the coating layer at that moment. This means that the offset yield stress of the anodized coating is about $80 \mathrm{MPa}$, which is lower than that of the coating-substrate beam $(96 \mathrm{MPa})$ at $350 \mathrm{~V}$ (Table 1). Although the critical failure stress of this coating-substrate beam has been estimated by the above analysis method, the result needs to be verified by experimental results based on the SEM in-situ technology.

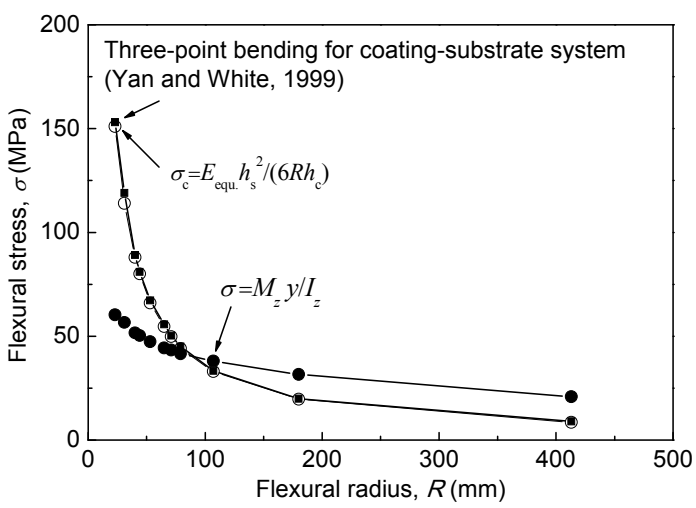

Fig. 4 Relationship between flexural stress and flexural radius

\subsection{Failure types of coating-substrate beam un- der three-point bending loading}

Fig. 5 shows a topically enlarged image of the cross-section of the coating-substrate structure with the interface. When the flexural stress reaches about $65 \mathrm{MPa}\left(\varepsilon_{\mathrm{c}}=1757 \mu \varepsilon\right.$, which is defined as the elastic range of the coating-substrate structure) based on Eq. (7), obvious cracks of about 3-5 $\mu \mathrm{m}$ were observed at the shrinkage defects in the coating layer and at the coating-substrate interface. This flexural stress was rather lower than the yield strength of the coating-substrate structure (Table 1) and the above mentioned estimated value of about $80 \mathrm{MPa}$. This reflects the fact that multiple cracks and interface delamination at the coating layer may occur during the elastic deformation process of the beam, especially near the shrinkage voids. This is because stress is concentrated in these micro regions. Another reason for the failure is that the flexural stress at the coating layer is a biaxial stress including the flexural stress and a restraint stress induced by plastic deformation in the width direction of the substrate. With increasing curvature of the beam (such as when the flexure stress reached about $88 \mathrm{MPa}\left(\varepsilon_{\mathrm{c}}=2378 \mu \varepsilon\right)$ based on Eq. (7)), the coating layer was subjected to a higher strength level so that fragmentation and spalling occurred and more cracks occurred at the substrate and coating layer (Fig. 6). The local fragmentation and spalling at the coating layer confirmed that the coating layer is subjected mainly to biaxial stress and the local coating completely lost the function of surface protection. Therefore, the critical deformation or flexural stress of the anodizing coatings can be obtained based on the failure analysis. That is, the critical flexural stress was estimated to be between 65 and $88 \mathrm{MPa}$ (the relative radius of the beam is between about 70 and $50 \mathrm{~mm}$ ). With increasing flexural stress (such as $100 \mathrm{MPa}$, $\varepsilon_{\mathrm{c}}=2703 \mu \varepsilon$ based on Eq. (7)), not only did the coating layer show complete spalling or delamination from the substrate at the flexural top of the beam (Fig. 7a), but also multiple macroscopic cracks formed in the substrate (Fig. 7b). Therefore, the coating-substrate beam suffered complete failure when the flexural stress reached $100 \mathrm{MPa}$. The failure characteristics of the anodized coating-substrate beam indicated that the types of failure were mainly multiple cracks in the coating layer and substrate, 
spalling of the coating layer, and interface cracks in the shrinkage region. Therefore, the SEM in-situ observation results indicated that the damage characteristics of the anodized coating-substrate beam can be summarized as follows: (1) the initiation and propagation of multiple cracks occurred mainly at the site of shrinkage in the coating layer and the interface. When the flexural stress reached about $88 \mathrm{MPa}$, multiple cracks propagated in the substrate and appeared discontinuous. (2) The propagation of macro cracks was not apparent either at the interface or inside the coating. This suggests that the adhesion between the anodized coating layer and the substrate is large enough not to induce interface crack propagation in the macro-scale, but some shrinkage occurs on the interface in the micro-scale. Shrinkage voids lead easily to crack initiation. (3) The spalling/ delamination of the coating layer occurred mainly in the vicinity of the maximum flexural stress point. One of the causes of failure due to spalling/ delamination is that the coating layer is subjected to the action of biaxial stress.

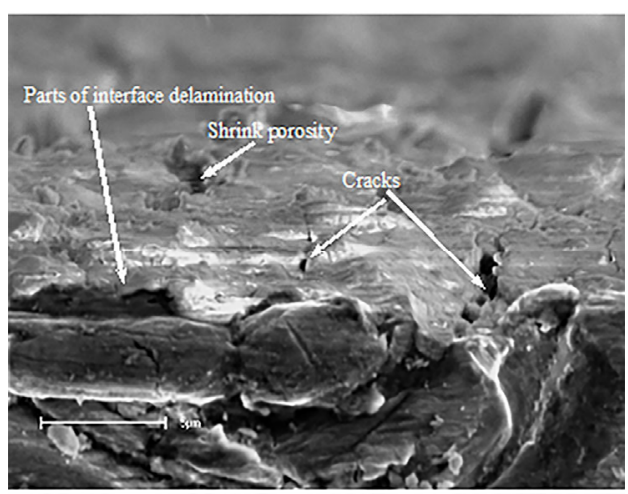

Fig. 5 Enlarged microstructure near the interface region (the flexural stress is $65 \mathrm{MPa}$, scale bar is $5 \mu \mathrm{m}$ )

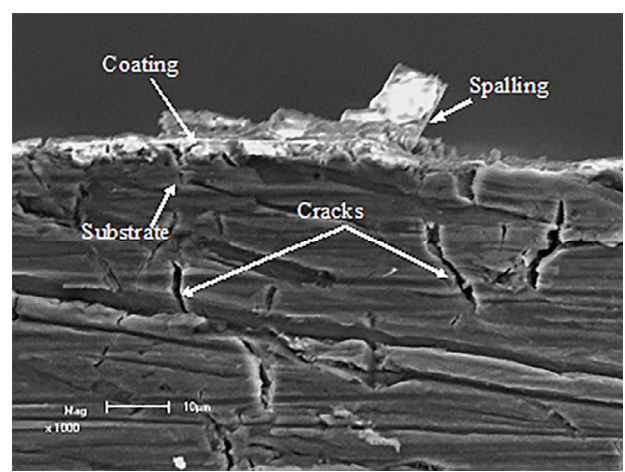

Fig. 6 SEM image at flexural stress $(88 \mathrm{MPa})$ based on Eq. (7) (scale bar is $10 \mu \mathrm{m}$ ) (a)

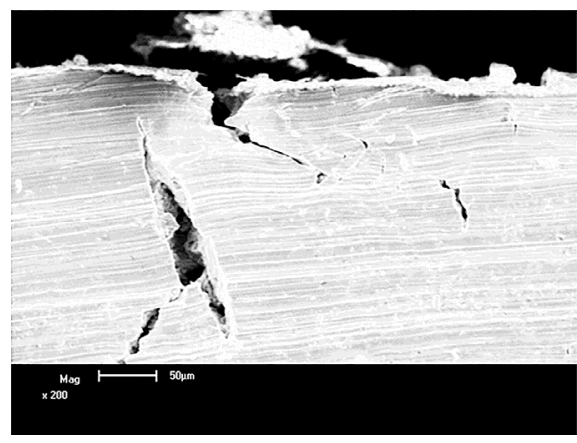

(b)

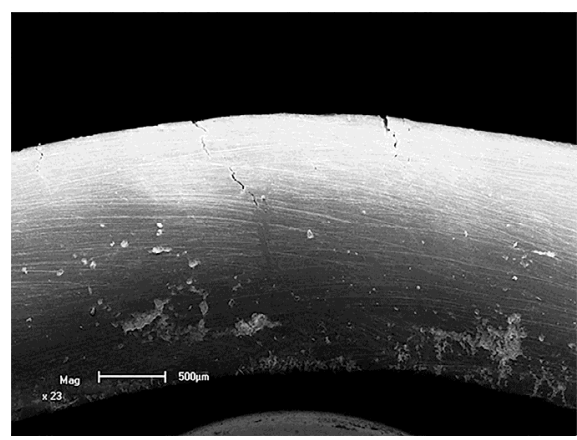

Fig. 7 (a) SEM image at the flexural stress (100 MPa) based on Eq. (7) (scale bar is $50 \mu \mathrm{m}$ ); (b) SEM image at the flexural stress (23 MPa) based on Eq. (7) (scale bar is $500 \mu \mathrm{m}, \boldsymbol{R}=\mathbf{3 0 0} \mathbf{~ m m}$ )

\subsection{Crack initiation at the interface based on dig- ital image correlation method analysis}

Although the cracking and debonding behaviors of the anodized coating-substrate beam can be characterized according the SEM in-situ images, the micro displacement and deformation fields on a crosssection of the beam close to the located failure regions during a discretional applied loading process can also be calculated and quantified using a digital image correlation method (DICM) (Vendroux and Knauss, 1998; Wang and Kang, 2002; Ma and Jin, 2003; Zuo et al., 2010; Li et al., 2013). DICM uses patterns of two SEM in-situ images from the same area under different bending curvatures. SEM images with and without deformation are compared using a pixel and its signature. If an initial deformation state in a small region of the SEM image is chosen as the reference subset, any other deformation state in another SEM image that corresponds to the initial deformation state can be defined as the target subset of image patterns. The two subsets share a relationship between the deformation field, and more importantly, the deformed region. Therefore, the 
measurable mismatched deformation is changed to compare the extent to which subsets move between the two images. A mathematical correlation coefficient $U^{*}\left(u^{*}, v^{*}\right)$ for determining deformation parameters of the gray levels was used to obtain the displacement components $u(x, y)$ and $v(x, y)$ between the speckle variation in two SEM images, in the $x$ and $y$ directions, respectively, as follows:

$$
U^{*}\left(u^{*}, v^{*}\right)=1-\frac{\sum f_{i}(x, y) \times \sum g_{i}\left(x^{*}, y^{*}\right)}{\sqrt{\sum f_{i}^{2}(x, y) \times \sum g_{i}^{2}\left(x^{*}, y^{*}\right)}},
$$

where $u^{*}, v^{*}$ are the $x$-displacement and $y$ displacement, respectively. $f_{i}(x, y), g_{i}\left(x^{*}, y^{*}\right)$ are the gray levels at any point in the reference and deformed images, respectively. The searching correlation was carried out among sub-matrices for each pixel with different values of $u^{*}$ and $v^{*}$. The correlation coefficient $U^{*}$ indicates how closely the two subsets are related. The matching point is obtained when $U^{*}$ reaches a maximum value where the parameters satisfy $u^{*}=u$ and $v^{*}=v$, from which the displacement components $u(x, y)$ and $v(x, y)$ can be determined by searching the overlapping subsets in the whole image. Therefore, $U^{*}=0$ corresponds to image correlation. Because there are systematic errors, random errors, and distortion of images, the correlation coefficient $U^{*}$ cannot equal 0 . That is, the minimum of $U^{*}$ is considered a coincidence of the assumed displacement and strain values with the actual deformation components. Thus, the deformation or displacement measurement becomes an optimization process of repeated iteration calculation for the minimum of $U^{*}$. In this section, the SEM and DICM are combined to quantitatively evaluate the micro deformation of the surface of the coating-substrate beam. The key characteristics of the analysis method are that it is more suitable for identifying deformation at a micro scale and is able to make adequate use of the variation in gray levels with the obvious concave-convex characteristic in the SEM in-situ images (Zuo et al., 2010). Based on the above mentioned principles and advantages of DICM, two SEM images each with different magnifications of 500, 1000 , and 2000 times were compared. At the $95 \%$ confidence interval, there was a resolution that was about 0.007 to 0.048 of the SEM images. Therefore, this indicated that the precision of the results was less than 0.05 pixels. In the SEM in-situ observation images, the actual length was 0.95 pixels $/ \mu \mathrm{m}$ and the accuracy of the DICM was 0.05 pixels. Therefore, the error range of the analysis result was about $0.01 \mu \mathrm{m}$.

Fig. 8 shows the estimated deformation level according to the displacement change in the Langrage coordinate by using a mathematical computing software package code (Sharpe et al., 2007; Eberl et al., 2010), which can also be used for calculating other parameters. We found that the result produced by this software agreed with the previous results (Figs. 5 and 6). For example, the maximum relative displacement determined using the mathematical computing software package was about $10.5 \mu \mathrm{m}$. To reduce the error and to obtain an accurate deformation field or the deformation mismatch points close to the interface between the anodized coating and the AZ91D substrate, the mathematical computing software package can be used to filter some noise in the distortion image. The peak values of strain distribution in the $y$-direction indicated that the strain variation was not more than $2500 \mu \varepsilon$ and the inferior peak value of the strain was about $1000 \mu \varepsilon$. This means that the peak value of about $1000 \mu \varepsilon$ is the critical deformation value between the anodized coating and the AZ91D substrate. This result of about 1000$2500 \mu \varepsilon$ strain roughly corresponds to the critical failure stress (biaxial stress) of about 45-100 MPa. As mentioned above, the failure stress of the anodized coating-AZ91D substrate structure was from about $65 \mathrm{MPa}$ to $88 \mathrm{MPa}$ based on SEM in-situ observations and using Eq. (7). Therefore, DICM

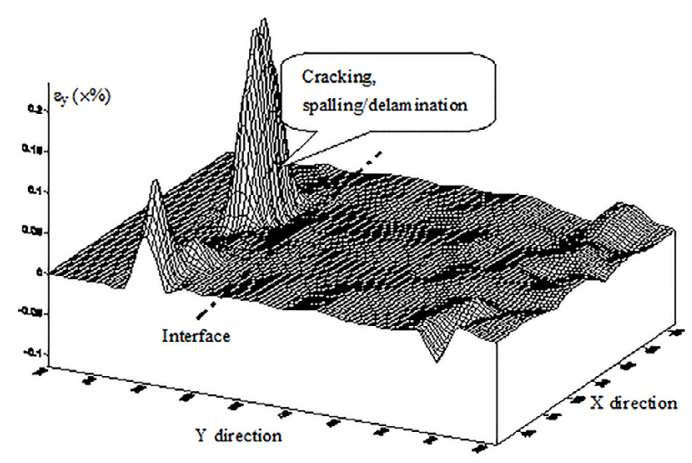

Fig. 8 Strain distributions near the interface based on DICM technology 
technology can be used not only to evaluate the failure point qualitatively, but also to estimate roughly the critical failure stress or strain of the anodized coating-AZ91D substrate (Fig. 8). The failure strain ranges of the coating layer estimated using DICM and Eq. (7) based on the SEM in-situ measurement method were in good agreement. This is because the coating layer is subjected to biaxial stress, not uniaxial stress, and because of the material's tensile modulus effects.

\section{Conclusions}

The quantitative evaluation of failure of an anodized coating-substrate beam based on the flexural radius $R$ of a beam with a thin coating layer was investigated using SEM in-situ observations and DICM. The main results obtained from this study were as follows:

1. The adhesion between the anodized coating layer and the substrate was large enough not to cause interface crack propagation even if an interface crack was initiated. The anodized coating layer had good interface strength.

2. Evaluation of flexural stress under threepoint bending loading using Eqs. (7) and (8) was more suitable for the coating-substrate structure than evaluation based on Eq. (2). There was a less than $5 \%$ difference between estimates obtained using Eqs. (7) and (8), but the method based on Eq. (7) is simpler. The critical stress of failure (65 MPa) was obtained for the anodized coating-substrate structure under three-point bending loading. The stress was biaxial, including the flexural stress and a restraint stress induced by plastic deformation of the substrate.

3 . The types of failure of an anodized coatingsubstrate beam under flexural stress are multiple cracks at the coating layer, interface, or substrate. Cracks at the interface and in the coating layer are formed preferentially. However, as the flexural stress increases, multiple cracks are initiated and propagated in the substrate. These are accompanied by spalling/delamination of the coating layer in the vicinity of the maximum flexural stress point when the flexural stress is more than $88 \mathrm{MPa}$, which is lower than the yield strength of an anodized coatingAZ91D substrate structure at $350 \mathrm{~V}$.
4. Estimates of the range of the failure strain of the coating layer obtained using DICM were in good agreement with those obtained using Eq. (7) based on SEM in-situ measurement method. This is because the coating layer is subjected to biaxial stress rather than uniaxial stress, and because of the material's tensile modulus effects.

\section{References}

Dahle, A.K., Lee, Y.C., Nave, M.D., et al., 2001. Development of the as-cast microstructure in magnesiumaluminum alloys. Journal of Light Metals, 1(1):61-72. http://dx.doi.org/10.1016/S1471-5317(00)00007-9

Dean, J., Gu, T., Clyne, T.W., 2015. Evaluation of residual stress levels in plasma electrolytic oxidation coatings using a curvature method. Surface \& Coatings Technology, 269:47-53. http://dx.doi.org/10.1016/j.surfcoat.2014.11.006

Eberl, C., Gianola, D.S., Hemker, K.J., 2010. Mechanical characterization of coatings using microbeam bending and digital image correlation techniques. Experimental Mechanics, 50(1):85-97. http://dx.doi.org/10.1007/s11340-008-9187-4

Eifert, A.J., Thomas, J.P., Rateick, R.G., 1999. Influence of anodization on the fatigue life of WE43A-T6 magnesium. Scripta Materialia, 40(8):929-935. http://dx.doi.org/10.1016/S1359-6462(99)00040-8

Fawcett, N., 1998. A novel method for the measurement of Young's modulus for thick-film resistor material by flexural testing of coated beams. Materials Science and Technology, 9:2023-2026. http://dx.doi.org/10.1088/0957-0233/9/12/015

Guo, X.W., Chang, J.W., He, S.M., et al., 2007. Investigation of corrosion behaviors of Mg-6Gd-3Y-0.4Zr alloy in $\mathrm{NaCl}$ aqueous solutions. Electrochimica Acta, 52(7): 2570-2579.

http://dx.doi.org/10.1016/j.electacta.2006.09.010

Huang, J.G., Wang, X.S., Meng, X.K., 2007. SEM in situ study on deformation behavior of $\mathrm{Cu}$ and $\mathrm{Cu} / \mathrm{Ni}$ films under three-point bending. Materials Transactions, 48(10):2795-2798. http://dx.doi.org/10.2320/matertrans.MRP2007069

Hutchinson, J.W., Suo, Z., 1991. Mixed mode cracking in layered materials. In: Hutchinson, J.W., Wu, T.Y. (Eds.), Advances in Applied Mechanics. Academic Press, USA, p.63-191.

Jia, S., Wang, X.S., Ren, H.H., 2012. Experimental and theoretical analysis of package $(\mathrm{PoP})$ structure under three points bending loading. Chinese Physics B, 21(12): 126201.

http://dx.doi.org/10.1088/1674-1056/21/12/126201

Konsta-Gdoutos, M.S., Gdoutos, E.E., 2005. The effect of load and geometry on the failure models of sandwich beams. Applied Composite Materials, 12(3-4):165-176. http://dx.doi.org/10.1007/s10443-005-1120-8 
Khan, R.H.U., Yerokhin, A.L., Pikington, A., et al., 2005. Residual stresses in plasma electrolytic oxidation coatings on Al alloy produced by pulsed unipolar current. Surface \& Coatings Technology, 200(5-6):1580-1594. http://dx.doi.org/10.1016/j.surfcoat.2005.08.092

Li, H., Khor, K.A., Cheang, P., 2002. Young's modulus and fracture toughness determination of high velocity oxyfuel-sprayed bioceramic coatings. Surface and Coatings Technology, 155(1):21-32. http://dx.doi.org/10.1016/S0257-8972(02)00026-9

Li, J.Y., Lau, A., Fok, A.S.L., 2013. Application of digital image correlation to full-field measurement of shrinage strain of dental composites. Journal of Zhejiang University-SCIENCE A (Applied Physics \& Engineering), 14(1):1-10.

http://dx.doi.org/10.1631/jzus.A1200274

Li, Y., Wang, X.S., Meng, X.K., 2008a. Buckling behavior of metal film/substrate structure under pure bending. Applied Physics Letters, 92(13):131902. http://dx.doi.org/10.1063/1.2897035

Li, Y., Wang, X.S., Fan, Q.S., 2008b. Effects of elastic anisotropic on the surface stability of the film/substrate system. International Journal of Engineering Science, 46(12):1325-1333. http://dx.doi.org/10.1016/j.ijengsci.2008.07.008

Ma, S.P., Jin, G.C., 2003. Digital speckle correlation method improved by genetic algorithm. Acta Mechanics Solida Sinica, 16(4):366-373.

Michler, J., Blank, E., 2001. Analysis of coating fracture and substrate plasticity induced by spherical indentors: diamond and diamond-like carbon layers on steel substrates. Thin Solid Films, 381(1):119-134. http://dx.doi.org/10.1016/S0040-6090(00)01340-7

Mordike, B.L., Ebert, T., 2001. Magnesium propertiesapplications - potential. Materials Science and Engineering: $A, \mathbf{3 0 2}(1): 37-45$. http://dx.doi.org/10.1016/S0921-5093(00)01351-4

Nykyforchyn, H.M., Klapkiv, M.D., Posuvailo, V.M., 1998. Properties of synthesised oxide ceramic coatings in electrolyte plasma on aluminium alloys. Surface \& Coatings Technology, 100-101:219-221. http://dx.doi.org/10.1016/S0257-8972(97)00617-8

Rajasekaran, B., Raman, S.G.S., Krishna, L.R., et al., 2008. Influence of microarc oxidation and hard anodizing on plain fatigue and fretting fatigue behaviour of Al-Mg-Si alloy. Surface \& Coatings Technology, 202(8):14621469. http://dx.doi.org/10.1016/j.surfcoat.2007.06.058

Ren, H.H., Wang, X.S., 2014. Fatigue damage behavior of a surface-mount electronic package under different cyclic loadings. Chinese Physics B, 23(4):044601. http://dx.doi.org/10.1088/1674-1056/23/4/044601

Ren, H.H., Wang, X.S., Jia, S., 2013. Fracture analysis on die attach adhesives for stacked packages based on in-situ testing and cohesive zone model. Microelectronics Reliability, 53(7):1021-1028. http://dx.doi.org/10.1016/j.microrel.2013.04.001

Schwaiger, R., Kraft, O., 2003. Size effects in the fatigue behavior of thin Ag films. Acta Materialia, 51(1):195202. http://dx.doi.org/10.1016/S1359-6454(02)00391-9

Sharpe, W.N., Pulskamp, J., Gianola, D.S., et al., 2007. Strain measurements of silicon dioxide microspecimens by digital imaging processing. Experimental Mechanics, 47(5): 649-658. http://dx.doi.org/10.1007/s11340-006-9010-z

Stoney, G.G., 1909. The tension of metallic films deposited by electrolysis. Proceedings of the Royal Society A: Mathematical, Physical and Engineering Sciences, 82(553):172-175. http://dx.doi.org/10.1098/rspa.1909.0021

Tang, B., Li, S.S., Wang, X.S., et al., 2005. Effect of $\mathrm{Ca} / \mathrm{Sr}$ composite addition into AZ91D alloy on hot-crack mechanism. Scripta Materialia, 53(9):1077-1082. http://dx.doi.org/10.1016/j.scriptamat.2005.06.039

Tvergaard, V., 2001. Crack growth predications by cohesive zone model for ductile fracture. Journal of the Mechanics and Physics of Solids, 49(9):2191-2207. http://dx.doi.org/10.1016/S0022-5096(01)00030-8

Tvergaard, V., 2004. Prediction of mixed mode interface crack growth using a cohesive zone model for ductile fracture. Journal of The Mechanics and Physics of Solids, 52(4):925-940. http://dx.doi.org/10.1016/S0022-5096(03)00115-7

Vendroux, G., Knauss, W.G., 1998. Submicron deformation field measurement: Part 2. Improved digital image correlation. Experimental Mechanics, 38(2):86-92. http://dx.doi.org/10.1007/BF02321649

Wang, H.W., Kang, Y.L., 2002. Improved digital speckle correlation method and its application in fracture analysis of metallic foil. Optical Engineering, 41(11):27932798. http://dx.doi.org/10.1117/1.1511749

Wang, X.S., Xu, Y., 2003. Mechanical characterizations of the dispersion $\mathrm{U}_{3} \mathrm{Si}_{2}-\mathrm{Al}$ fuel plate with sandwich structure under tensile loading. Applied Composite Materials, 10(3):159-167. http://dx.doi.org/10.1023/A:1023978413329

Wang, X.S., Xu, Y., 2004. Experiments, characterizations and analysis of a dispersion $\mathrm{U}_{3} \mathrm{Si}_{2}-\mathrm{Al}$ fuel plate with sandwich structure. Journal of Nuclear Materials, 328(23):243-248. http://dx.doi.org/10.1016/j.jnucmat.2004.04.332

Wang, X.S., Fan, J.H., 2006. An evaluation the growth rate of small fatigue cracks in cast AM50 magnesium alloy at different temperature in vacuum environment. International Journal of Fatigue, 28(1):79-86. http://dx.doi.org/10.1016/j.ijfatigue.2005.03.004

Wang, X.S., Xu, Y., Xu, X.Q., 2004. Direct observations of microcracking in the fuel plate using the scanning electron microscope. Applied Composite Materials, 11(3): 
$145-154$.

http://dx.doi.org/10.1023/B:ACMA.0000026478.76133.7a

Wang, X.S., Li, Y., Meng, X.K., 2009. An estimation method on failure stress of micro thickness $\mathrm{Cu}$ film-substrate structure. Science in China Series E: Technological Sciences, 52(8):2210-2215.

http://dx.doi.org/10.1007/s11431-009-0235-9

Wang, X.S., Guo, X.W., Li, X.D., et al., 2014. Improvement on the fatigue performance of 2024-T4 alloy by synergistic coating technology. Materials, 7(5):3533-3546. http://dx.doi.org/10.3390/ma7053533

Wang, X.S., Li, X.D., Yang, H.H., et al., 2015. Environmentinduced fatigue cracking behavior of aluminum alloys and modification methods. Corrosion Reviews, 33(34):119-137. http://dx.doi.org/10.1515/corrrev-2014-0057

Yan, G., White, J.R., 1999. Residual stress development in a Bi-layer coating. Polymer Engineering and Science, 39(10):1856-1865.

http://dx.doi.org/10.1002/pen.11579

Yang, C., Shen, Y.B., Luo Y.Z., 2014. An efficient numerical shape analysis for light weight membrane structures. Journal of Zhejiang University-SCIENCE A (Applied Physics \& Engineering), 15(4):255-271. http://dx.doi.org/10.1631/jzus.A1300245

Yerokhin, A.L., Nie, X., Leyland, A., et al., 1999. Plasma electrolysis for surface engineering-Review. Surface \& Coatings Technology, 122(2-3):73-93. http://dx.doi.org/10.1016/S0257-8972(99)00441-7

Yerokhin, A.L., Shatrov, A., Samsonov, V., et al., 2004. Fatigue properties of Keronite coating on a magnesium alloy. Surface \& Coatings Technology, 182(1):78-84. http://dx.doi.org/10.1016/S0257-8972(03)00877-6

Yerokhin, A.L., Shatrov, A., Samsonov, V., et al., 2005. Oxide ceramic coatings on aluminium alloys produced by a pulsed bipolar plasma electrolytic oxidation process. Surface \& Coatings Technology, 199(2-3):150-157. http://dx.doi.org/10.1016/j.surfcoat.2004.10.147

Zhao, M.H., Fu, R., Lu, D., et al., 2002. Critical thickness for cracking of $\mathrm{Pb}\left(\mathrm{Zr}_{0.53} \mathrm{Ti}_{0.47}\right) \mathrm{O}_{3}$ thin films deposited on
Pt/Ti/Si(1100) substrates. Acta Materialia, 50(17):42414254.

http://dx.doi.org/10.1016/S1359-6454(02)00254-9

Zuo, J.P., Wang, X.S., Zuo, M., 2010. Micro deformation testing of cast AM60B Mg alloy based on scanning electron microscope and digital image correlation method. Materials Evaluation, 68(9):1030-1036.

\section{中文概要}

题 目: 氧化涂层与基体临界失效应力的扫描电镜原位 试验研究

目 的: 以典型的氧化涂层-AZ91D 基体材料为背景, 开 展涂层-基体结构的损伤行为研究, 在扫描电镜 原位试验基础上定量地评价这种结构材料的临 界弯曲失效应力值。

创新点: 在 Stoney 方程基础上首次用试验方法定量地表 征氧化涂层与镁铝合金基体材料的弯曲失效应 力值; 建立梁或板最大弯曲扰度与临界失效应 力之间的关系, 弥补 Stoney 方程中没有考虑二 维效应及涂层材料特性引起的不足, 使之更加 适合工程中常见涂层-基体结构的损伤特点。

方 法: 将如图 1 所示的涂层-基体结构试件断面仔细抛 光后置于扫描电镜的真空腔内; 边加载边观察 断面中损伤行为的变化, 特别是界面附近的变 形和开裂状态; 比较所对应的加载点位移和载 荷大小, 并把其作为评价损伤行为的力学 参数。

结 论: 本试验方法定量表征的涂层-基体结构临界弯曲 失效应力值和失效位置与扫描电镜损伤演化图 形的数字散斑分析结果一致, 适合二维涂层-基 体结构损伤应力的评价。

关键词: 氧化涂层; 弯曲应力; 界面力学; 扫描电镜原 位观测技术 